\title{
Aspectos Estruturais e Fitoquímicos de partes vegetativas de Costus spicatus (Jacq.) Sw. (Costaceae)
}

PAES, L.S..$^{*} ;$ MENDONÇA, M. S. ${ }^{2} ;$ CASAS, L.L. ${ }^{3}$

1IFAM - Instituto Federal do Amazonas, Avenida 7 de Setembro, $n^{\circ} 1975$ - Centro, CEP: 69020-120, ManausBrasil *luci@ifam.edu.br. ${ }^{2}$ Universidade Federal do Amazonas (UFAM). Laboratório de Botânica Agroflorestal (LABAF); CEP: Av. General Rodrigo Octávio Jordão Ramos, $n^{\circ} 3000$, Campus Universitário, Coroado I CEP:69077-000, Manaus-Brasil. 3Iniciação Científica - FAPEAM, Avenida 7 de Setembro, $n^{\circ} 1975$ - Centro, CEP: 69020-120, Manaus-Brasil.

\begin{abstract}
RESUMO: As folhas de Costus spicatus são amplamente empregadas na medicina popular para o tratamento de várias doenças entre elas: malária, hepatite e doença do aparelho urinário. O objetivo deste trabalho foi identificar aspectos da anatomia dos órgãos vegetativos (folhas, caules, raízes e rizomas) associados à triagem fitoquímica visando contribuir com informações relevantes para o desenvolvimento de estudos taxonômicos e farmacológicos. A análise anatômica por meio da microscopia óptica e de varredura evidenciou folha anfi-hipoestomática, com estômatos e tricomas tectores filamentosos simples. O mesofilo é constituído por parênquima clorofiliano, que se divide em duas regiões intercaladas por cordão de fibras e feixes vasculares. O caule é do tipo atactostélico como no rizoma. A raiz é poliarca. Os testes histoquímicos indicaram a presença de amido, proteínas estruturais, alcaloides, cristais de oxalato de cálcio. A prospecção química com extratos hidroalcoólico e aquoso constatou a presença de saponinas, taninos, alcaloides, compostos fenólicos e heterosídeos cianogênicos.
\end{abstract}

Palavras chaves: anatomia, metabólitos secundários, plantas medicinais, Costus spicatus

\begin{abstract}
Structural and Phytochemical aspect from vegetative part of Costus spicatus (Jacq.) Sw (Costaceae). The leaves of Costus spicatus are widely employed in folk medicine for the treatment of several diseases, including: malaria, hepatitis and urinary tract disease. The purpose of this paper was to identify aspects of the anatomy of vegetative organs (leaves, stems, roots and rhizomes) associated with phytochemical screening to contribute with relevant information for the development of taxonomic and pharmacological studies. The anatomic analysis through optical microscopy and scanning showed amphistomatic leaves with tetracitic type stomats and simple filamentous tector trichomes. Mesophyll is constituted by a chlorophyllian parenchyma, which is divided into two regions intersected by a strand of fibers and vascular bundles. The stem is atactostelic, such as for the rhizome. The root is polyarc. The histochemical tests indicated the presence of structural proteins, alkaloids, and calcium oxalate crystals. Chemical prospecting with hydroalcoholic and aqueous extracts attested the presence of saponins, tannins, alkaloids, phenolic compounds and heterosides as cyanogenic glucosides.
\end{abstract}

Keywords: anatomy, secondary metabolites, medicinal plants, Costus spicatus

\section{INTRODUÇÃO}

Costus spicatus (Jacq.) Sw é uma espécie herbácea com distribuição neotropical pertencente à família Costaceae (Specht et al., 2001; Specht \& Stevenson, 2006; A.P.G III, 2009). Trata-se de uma planta perene, cespitosa, cuja parte aérea pode atingir 1,0 a 2,0 metros de altura, nativa em quase todo Brasil, principalmente na Mata Atlântica e região Amazônica (Lorenzi \& Matos, 2008). As folhas são dispostas em espiral com prolongamento invaginante na base formando ócrea, com inflorescência terminal, brácteas em espiral, densa, imbricadas, glabra, e vermelha (Petersen, 1990).

Em virtude da semelhança quanto à morfologia e aplicações, as denominações populares de representantes do gênero Costus são: canamansa, canarana, cana-de -macaco, pobre-velho e cana-do-brejo (Borrás, 2003; Lorenzi \& Matos, 
2008). Costus spiralis Rosc. e Costus spicatus (Jacq.) Sw são conhecidas por apresentarem as mesmas utilizações na medicina tradicional (Gasparri, 2005).

$\mathrm{Na}$ medicina popular brasileira, o chá de C. spicatus é utilizado com fins depurativos, adstringentes e diuréticos (Boorhem et al., 1999; Borrás, 2003). Boorhem et al. (1999) descrevem que a decocção das partes vegetativas da espécie atuam no tratamento de irritações vaginais, leucorreias e úlceras. O suco do caule fresco diluído é eficaz no tratamento de gonorreia, sífilis, nefrite, picada de insetos, problemas de bexiga e diabetes (Albuquerque, 1989; Borrás, 2003). As folhas podem ser combinadas com Bonamia ferruginea "cipótuíra" (Choisy) Hallier em forma de combinações (garrafadas) no tratamento da malária, hepatite e diabetes (Silva, 2004).

Os registros científicos indicam que o uso do chá das folhas de $C$. spicatus em experimentos com ratos durante 6 a 16 semanas para avaliação da progressão da hiperglicemia e insulinopenia entre os grupos experimentais e controle foram estatisticamente indistinguíveis demonstrando que 0 chá não promoveu a diminuição da progressividade da diabetes mellitus tipo 2 (Keller et al., 2009) resultados também observados por Silveira et al. (2010) com utilização de extrato metanólico em doses de 100, 200 e $400 \mathrm{mg} / \mathrm{kg}$. De acordo com Pinna et al., (2008) o chá de C. spicatus é eficaz no tratamento de Herpes zoster. Para Silva et al. (2000) a atividade anti-inflamatória encontrada no extrato foliar está relacionada a presença dos glicosídeos flavônicos.

A família Costaceae anteriormente classificada como uma subfamília de Zingiberaceae (Costoideae) recentemente foi reclassificada em função da análise cladística molecular do genoma nuclear de cloroplasto, bem como pelas características morfológicas as quais, indicam que há diferenças anatômicas e estruturais para Costaceae e Zingiberaceae que garantem um caráter diagnóstico distintivo (Specht \& Stevenson, 2006). No entanto, poucos trabalhos científicos evidenciam características peculiares de Costaceae.

Diante do exposto objetivou-se caracterizar os aspectos anatômicos das partes vegetativas de C. spicatus identificando as principais classes de metabólitos secundários existentes nos tecidos como forma de contribuir com informações que forneçam subsídios para estudos taxonômicos, agronômicos, fisiológicos e farmacológicos referentes à família.

\section{MATERIAIS E MÉTODOS}

O material botânico (folhas, caules, raízes e rizomas) foi coletado no Campus Setor Sul da Universidade Federal do Amazonas. Foram selecionados e coletados 60 indivíduos adultos (10 indivíduos para estudo anatômico e 50 indivíduos para avaliação fitoquímica). As exsicatas encontramse inseridas no acervo do Herbário HUAM da Universidade Federal do Amazonas - UFAM sob número de registro 8288 .

\section{Microscopia de luz}

Para o estudo anatômico, amostras das partes vegetativas (folhas, caules, raízes e rizomas), foram fixadas em FAA 70 (formaldeído, ácido acético glacial e álcool etílico $70 \%$ ) e estocadas em álcool etílico $70 \%$. Posteriormente, o material foi desidratado em série etílica e infiltrado em metacrilato (Historesin, Leica, preparada conforme as instruções do fabricante). Em micrótomo rotativo os blocos foram seccionados (5 a $10 \mathrm{~mm}$ de espessura) e as secções foram coradas em Azul de Toluidina pH 4,0 (O’Brien \& Maccully, 1981), sendo montadas em resina sintética.

Na preparação de lâminas semipermanentes foram utilizadas partes vegetativas seccionadas transversalmente a mão livre, clarificadas com solução comercial de hipoclorito de sódio a $20 \%$, coradas com azul de astra e fucsina e montadas em glicerina.

$\mathrm{Na}$ dissociação da epiderme, foram retiradas secções do ápice, borda e base da lâmina foliar e submetidas à solução de hipoclorito de sódio em diferentes concentrações (70-100\%) durante quatro dias. Em seguida, foram lavadas em álcool etílico, posteriormente coradas com solução aquosa azul de astra e safranina 1\%, e montadas em glicerina (Kraus \& Arduin, 1997). A classificação dos tricomas foi feita com base em Theobald (1979). As imagens foram obtidas com auxílio do microscópio óptico Axioskop com câmara MC 80.

Para os testes histoquímicos, secções das partes vegetativas do material fresco que não foram submetidas a reagentes foram fotografadas a fim de documentar a coloração original dos tecidos analisados (branco). Secções controle foram realizadas simultaneamente, de acordo com a metodologia descrita nos protocolos. As classes de metabólitos investigadas encontram-se descritas na Tabela 1.

\section{Eletromicrografia de varredura (MEV)}

Para a obtenção das eletromicrografias de varredura, secções fixadas em FAA $70 \%$ por 48 horas, pós-fixadas em tetróxido de ósmio a $1 \%$ foram desidratadas em série etílica crescente de acordo com Johansen (1940), processadas em secador de ponto crítico de $\mathrm{CO}_{2}$, aderidas em suportes metálicos através de fita de carbono dupla face e metalizadas com camada de ouro de aproximadamente $20 \mathrm{~nm}$

Rev. Bras. PI. Med., Campinas, v.15, n.3, p.380-390, 2013. 
TABELA 1. Testes histoquímicos aplicados em amostras frescas do material.

\begin{tabular}{|c|c|c|c|}
\hline & GRUPOS DE METABÓLITO & COLORAÇÃO & EM LUZ VISÍVEL \\
\hline \multirow[t]{2}{*}{ Lipídios } & Lipídios totais & vermelha & Sudan IV (Gerlach, 1984) \\
\hline & Compostos fenólicos gerais & verde, púrpura, azul, negro & Cloreto Férrico III (Johansen, 1940) \\
\hline \multirow{3}{*}{$\begin{array}{l}\text { Compostos } \\
\text { Fenólicos }\end{array}$} & Taninos & vermelha & Vanilina Clorídrica \\
\hline & & & (Mace \& Howell, 1974) \\
\hline & Lignina & vermelha & Floroglucinol (Johansen, 1940) \\
\hline \multirow[t]{2}{*}{ Alcaloides } & Alcaloides & castanho-avermelhado & Reagente de Drangendorff (Costa, 1982) \\
\hline & Amido & roxa & Lugol (Jensen, 1962) \\
\hline \multirow{2}{*}{$\begin{array}{l}\text { Polissacarídeos } \\
\text { Neutros }\end{array}$} & Pectinas e mucilagens & rosa intenso & Azul de Metileno \\
\hline & & & (Salatino \& Silva, 1975) \\
\hline \multirow[t]{2}{*}{ Proteínas } & Proteínasestruturais & laranja & Xilidine Ponceau \\
\hline & & & (O’Brien e McCully, 1981) \\
\hline \multirow[t]{3}{*}{ Terpenoides } & Óleos essenciais & azul (essência), vermelha & \\
\hline & e óleo-resinas & (resina), violeta & Reagente de Nadi (David e Carde, 1964) \\
\hline & & (essência+resina) & \\
\hline \multirow[t]{2}{*}{ Cristais } & Cristal de oxalato de cálcio & transparente & Solução de ácido clorídrico 10 \% \\
\hline & & & (Jensen, 1962) \\
\hline
\end{tabular}

de espessura por 150 segundos em corrente de $25 \mathrm{~mA}$. A observação e a captação de imagens foram realizadas no Laboratório de Microscopia do Museu Paraense Emílio Goeldi, em microscópio eletrônico de varredura LEO modelo 1450 VP, com aceleração de voltagem de $15 \mathrm{kV}$, sendo as escalas micrométricas projetadas nas mesmas condições ópticas.

\section{Prospecção fitoquímica}

A triagem e avaliação fitoquímica dos extratos aquoso e hidroalcoólico das partes de $C$. spicatus foram realizadas segundo a metodologia de Matos (1997).

Para avaliação do extrato aquoso, $40 \mathrm{~g}$ do material vegetal moído (serragem) foi pesado sendo submetido a $200 \mathrm{~mL}$ de $\mathrm{H}_{2} \mathrm{O}$ e, em seguida, levado ao banho-maria por 1 hora a $70^{\circ} \mathrm{C}$. Posteriormente foi filtrado, sendo o volume completado para 200 $\mathrm{mL}$ com o líquido extrator. Os extratos obtidos foram submetidos a testes para verificação da presença de: heterosídeos cianogênicos, (papel picro-sódico) heterosídeos saponínicos (agitação da solução) e ácidos voláteis (fitas de $\mathrm{pH}$ ).

Para a preparação do extrato hidroalcoólico foram pesadas as respectivas massas de serragem: $123,13 \mathrm{~g}$ de folhas; $340,40 \mathrm{~g}$ de raízes e rizoma; $500,00 \mathrm{~g}$ de caule, e em seguida submetidas ao processo de extração por maceração a frio em etanol $95 \%$ durante 7 dias e posteriormente o extrato foi filtrado. No término, os extratos foram evaporados em rotaevaporador. A solução-mãe foi preparada a partir de $200 \mathrm{mg}$ de cada parte vegetativa diluída em $10 \mathrm{~mL}$ de etanol PAe água (6:2). Os extratos obtidos foram submetidos a reações químicas seletivas para a identificação da presença de fenóis e taninos (reação com cloreto férrico), compostos fenólicos (teste de variação de $\mathrm{pH}$, com hidróxido de sódio e ácido sulfúrico), saponinas (teste de formação de espuma), alcaloides (reação com Dragendorff, Hager e Mayer).

\section{RESULTADOS E DISCUSSÃO}

\section{Caracterização Anatômica e Histoquímica}

Costus spicatus apresenta folhas elípticas dispostas em espiral no caule, com inflorescência em espigas estrobiliformes de brácteas vermelhas e flores amarelas (Figura 1 e 2).

\section{Folha}

A epiderme foliar em vista frontal apresenta células com paredes retas levemente onduladas com formato hexagonal. Os tricomas são do tipo tectores filamentosos simples, sem ramificações 


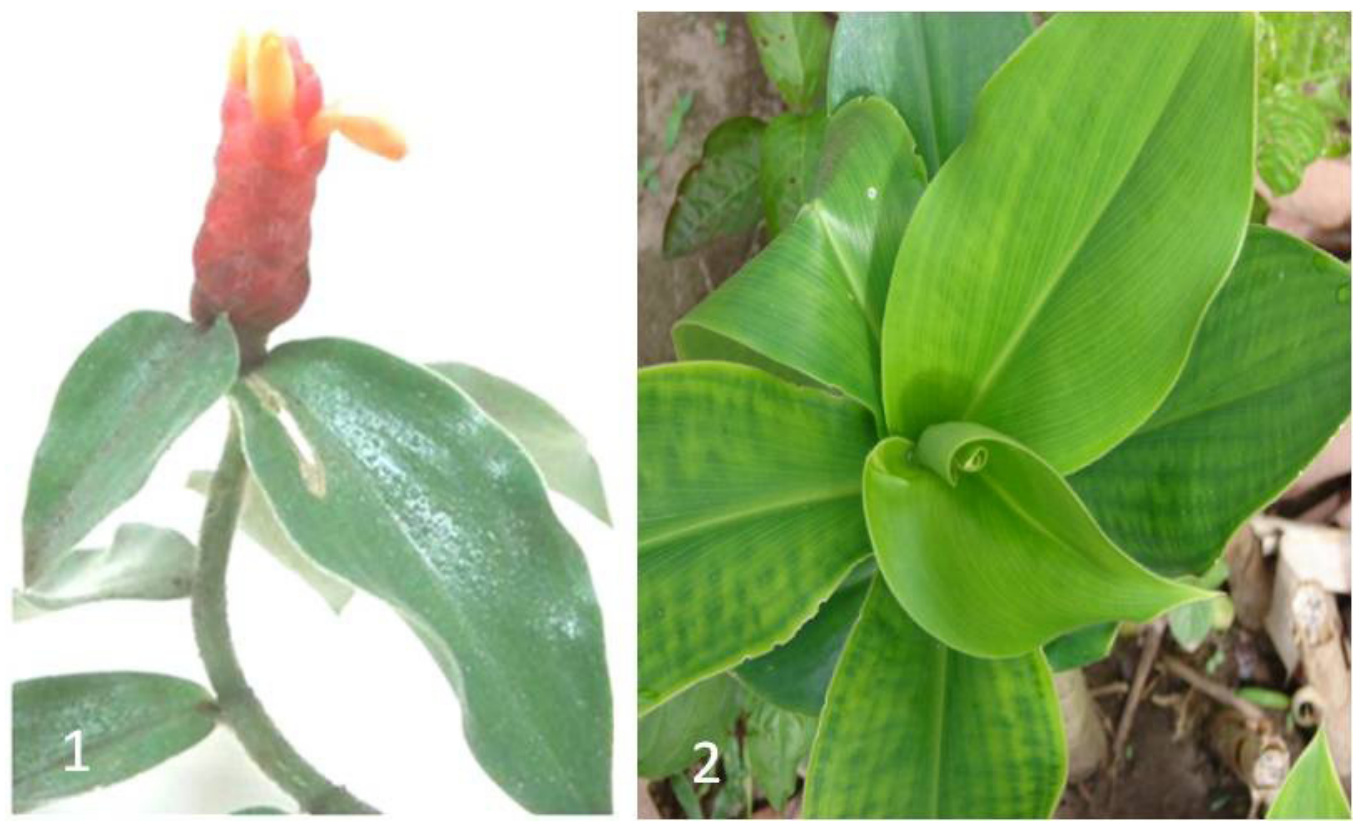

FIGURAS 1-2. Costus spicatus (Jacq.) Sw.1. Inflorescência. 2. Disposição das folhas em espiral.

(Figura 3) predominantes na face abaxial. De acordo com Tomlinson (1956; 1962) a morfologia dos tricomas, uniseriados, não ramificados, é caráter distintivo entre Costaceae e Zingiberaceae.

A folha é anfi-hipoestomática e os estômatos são do tipo tetracíticos (Figura 4) estas informações ainda não haviam sido descritas para a família Costaceae os registros desta disposição e forma de estômatos haviam sido relatadas apenas para Zingiberaceae a exemplo das folhas de 20 espécies pertencentes ao gênero Alpinia descritas por Hussin et al. (2000) e Albuquerque \& Neves (2004).

Secções transversais da folha evidenciam epiderme uniestratificada, revestida por cutícula, mais espessa na face abaxial. Sob a epiderme, a hipoderme apresenta-se em ambas as faces sendo constituída de duas camadas de células arredondadas com paredes delgadas (Figuras $5 \mathrm{e}$ 6). Na região da nervura mediana este tecido pode sofrer variações quanto ao número de células, em virtude do formato côncavo-convexo desta região (Figura 5). Specht \& Stevenson (2006) afirmaram que a variação no número de células da hipoderme tem um caráter distintivo para Costaceae, pois em Zingiberaceae pode ser ausente ou apresentar apenas uma camada simples ao contrário do que ocorre em Costaceae.

O mesofilo apresenta organização dorsiventral com parênquima paliçádico constituído por cerca de uma a duas camadas de células alongadas e justapostas. Nesta região, é observada grande quantidade de cristais e ausência de meatos resultando no aspecto denso. O parênquima lacunoso é constituído por cerca de duas a três camadas de células isodiamétricas (Figura 6).

As células da hipoderme são ricas em cristais de oxalato de cálcio (Figuras 7 e 9) corroborando os registros de Oliveira et al. (1986) para $C$. spiralis. Os cristais geralmente encontramse distribuídos entre todos os níveis taxonômicos de organismos fotossintéticos. O acúmulo de cristais nos vegetais, possivelmente, apresenta um aumento na capacidade de regulação do cálcio $(\mathrm{Ca})$ e atua na proteção contra herbivoria (Franceschi \& Nakata, 2005). Frequentemente, as células subepidérmicas são interrompidas pelas câmaras subestomáticas (Figura 8).

Os feixes vasculares são bicolaterais, envolvidos por calotas de fibras esclerenquimáticas, dispostas externamente ao xilema e ao floema (Figura 9).

Os principais testes histoquímicos destinados à visualização de compostos secundários foram realizados, mas somente foram evidenciados alcaloides e proteínas estruturais em células que compõe o mesofilo (Figura 10 e 11) respectivamente.

O caule aéreo em corte transversal possui uma haste central envolvida por duas a três bainhas foliares. Cada bainha apresenta a mesma estrutura da lâmina foliar revestida por tricomas tectores filamentosos simples (Figura 12-14).

Sob as bainhas foliares, a haste caulinar apresenta uma epiderme uniestratificada com células ligeiramente retangulares, revestida por cutícula delgada. O córtex é constituído por um parênquima clorofiliano formado por cerca de 2 a 4 camadas de células. A endoderme é distinta delimitando a região cortical, evidenciada pelas 

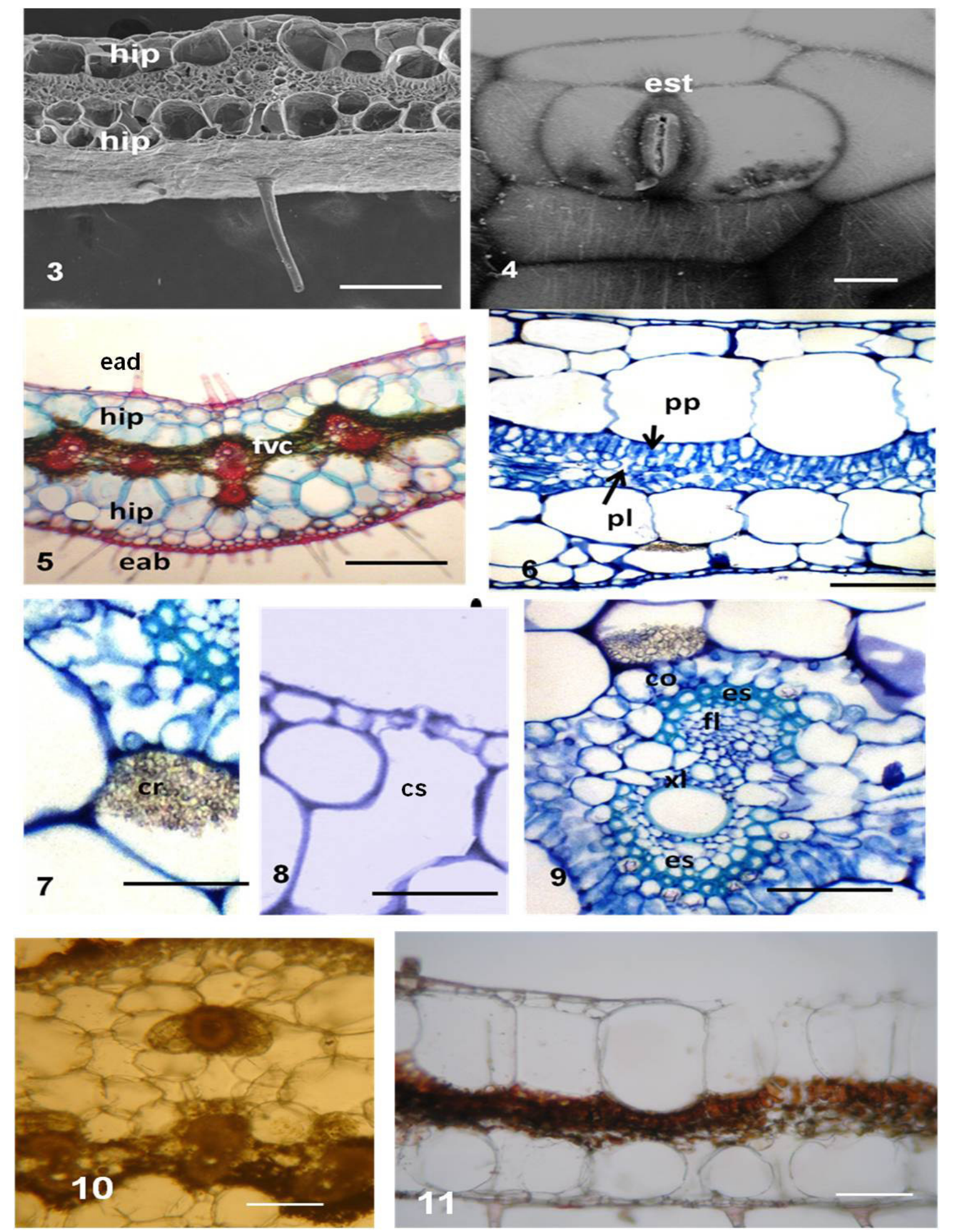

FIGURAS 3-11. Costus spicatus (Jacq.) Sw. 3. Corte transversal da lâmina foliar com tricomas tectores (MEV). 4. Estômatos (est) em vista frontal (MEV). 5-11.Secção transversal da lâmina foliar de Costus spicatus. 5. Nervura mediana com feixe vascular central (fvc) hipodermes (hip). Epiderme adaxial (ead). Epiderme abaxial (eab) 6.Mesofilo; parênquima paliçádico (pp) e lacunoso (pl). 7. Cristais de oxalato de cálcio (cr). 8. Câmara subestomática (cs). 9. Feixe vascular central: xilema (xl), floema (fl) e calotas de fibras de esclerênquima (es), colênquima (co). 10. Alcaloides em regiões próximos aos feixes vasculares. 11. Proteínas estruturais na região do mesofilo. Barras $=170 \mu \mathrm{m}$ (3 e 4), $100 \mu \mathrm{m}$ ( 6, 7, 8, 10,11), $5 \mu \mathrm{m}$ (5), $200 \mu \mathrm{m}$ (9). 

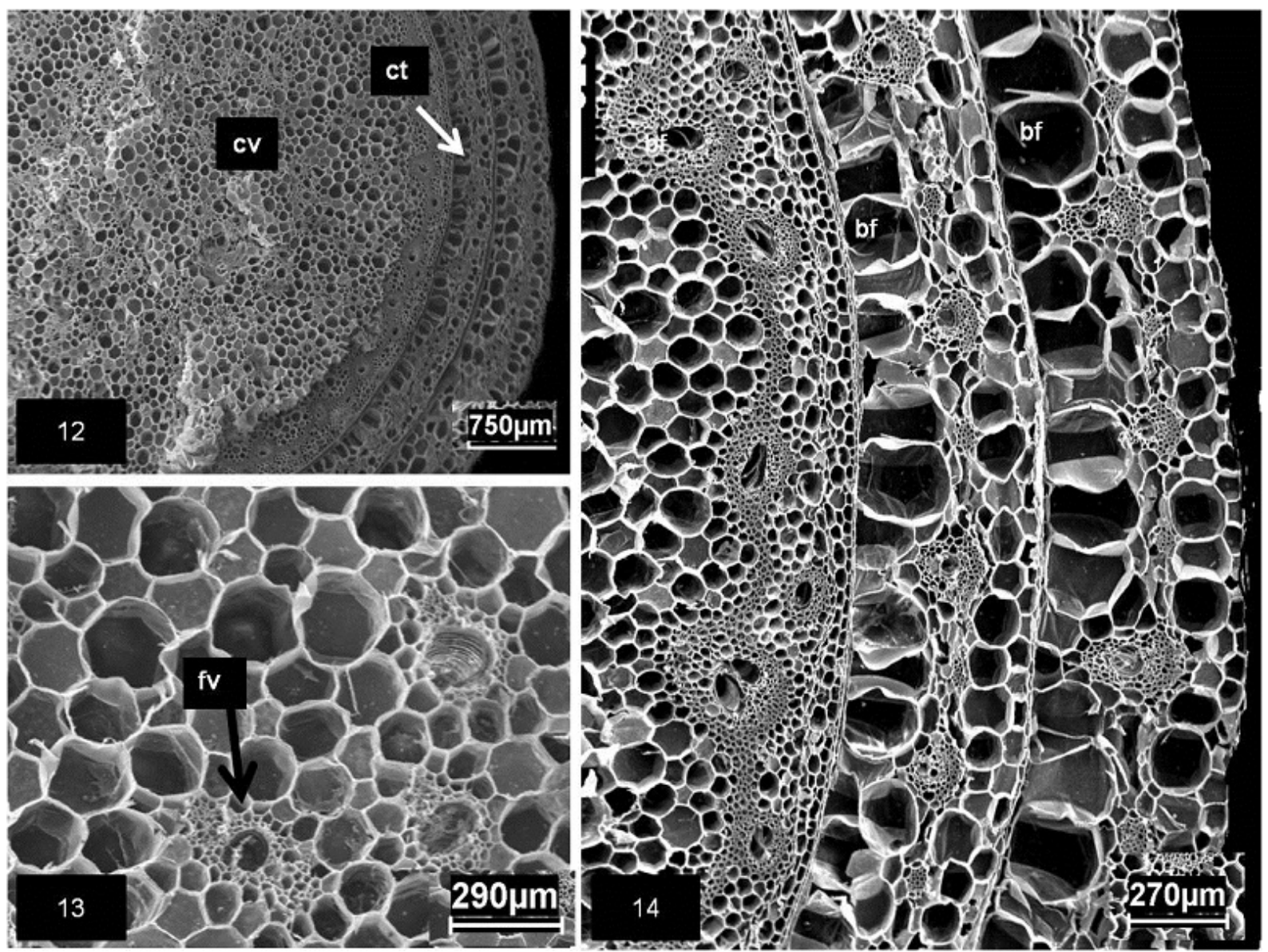

FIGURAS 12-14. Eletromicrografia de Varredura de seções transversais do caule de Costus spicatus (Jacq.) Sw. 12. Cilindro vascular (cv) e córtex (ct). 13. Feixes vasculares na região medular (fv) 14. Detalhe das bainhas foliares (bf).

estrias de Caspary (Figura 15 e 16). Appezzato-daGlória \& Carmello-Guerreiro (2006) afirmam que o córtex e a medula são muitas vezes contínuos em monocotiledôneas, mas sugerem que pode haver uma delimitação interna pela presença de camada endodérmica ou ocorrência de feixes vasculares.

O periciclo é composto por duas ou três fileiras de células com paredes espessadas e lignificadas coradas de rosa pelo floroglucinol (Figura 21) de tamanho reduzido que envolve tecidos vasculares (Figura 15). Menezes et al. (2005) afirmaram que o periciclo aparece sempre adjacente ao córtex, onde a endoderme e o periciclo constituem o meristema de espessamento primário. Para Silva (2009) ambos tecidos são responsáveis pelo espessamento do corpo primário das monocotiledôneas.

O tecido vascular é colateral com distribuição de feixes na região medular, determinando a classificação do tipo atactostélica (Figura 17).

As reações histoquímicas indicam que em células parenquimáticas que compõem o tecido do córtex apresentam reservas de compostos fenólicos (Figura 18), alcaloides (Figura 19) e nas células que compõem o cilindro vascular as reservas são de mucilagem (Figura 20) e amido (Figura 22).

\section{Rizoma}

O rizoma (caule subterrâneo) é bem desenvolvido classificado como atactostélico. É revestido por uma epiderme uniestratificada. A região cortical é formada por células parenquimáticas que apresentam formato isodiamétrico. A região central é delimitada pelas estrias de Caspary (Figuras 23 e 24). As células parenquimáticas que constituem o cilindro vascular têm formato arredondado com variações no tamanho, sendo portadoras de inúmeros grãos de amido (Figura 25). Segundo Tomlinson (1956) tanto em Costaceae como Zingiberaceae a presença de amido é intensa neste órgão.

\section{Raiz}

A raiz de $C$. spicatus, evidencia epiderme uniestratificada constituída por células de formato poligonal, revestida por pêlos radiculares (Figuras 26 e 27). Adjacente à epiderme, está localizada a exoderme composta de uma única camada de células, em seguida ocorrem várias camadas de

Rev. Bras. PI. Med., Campinas, v.15, n.3, p.380-390, 2013. 

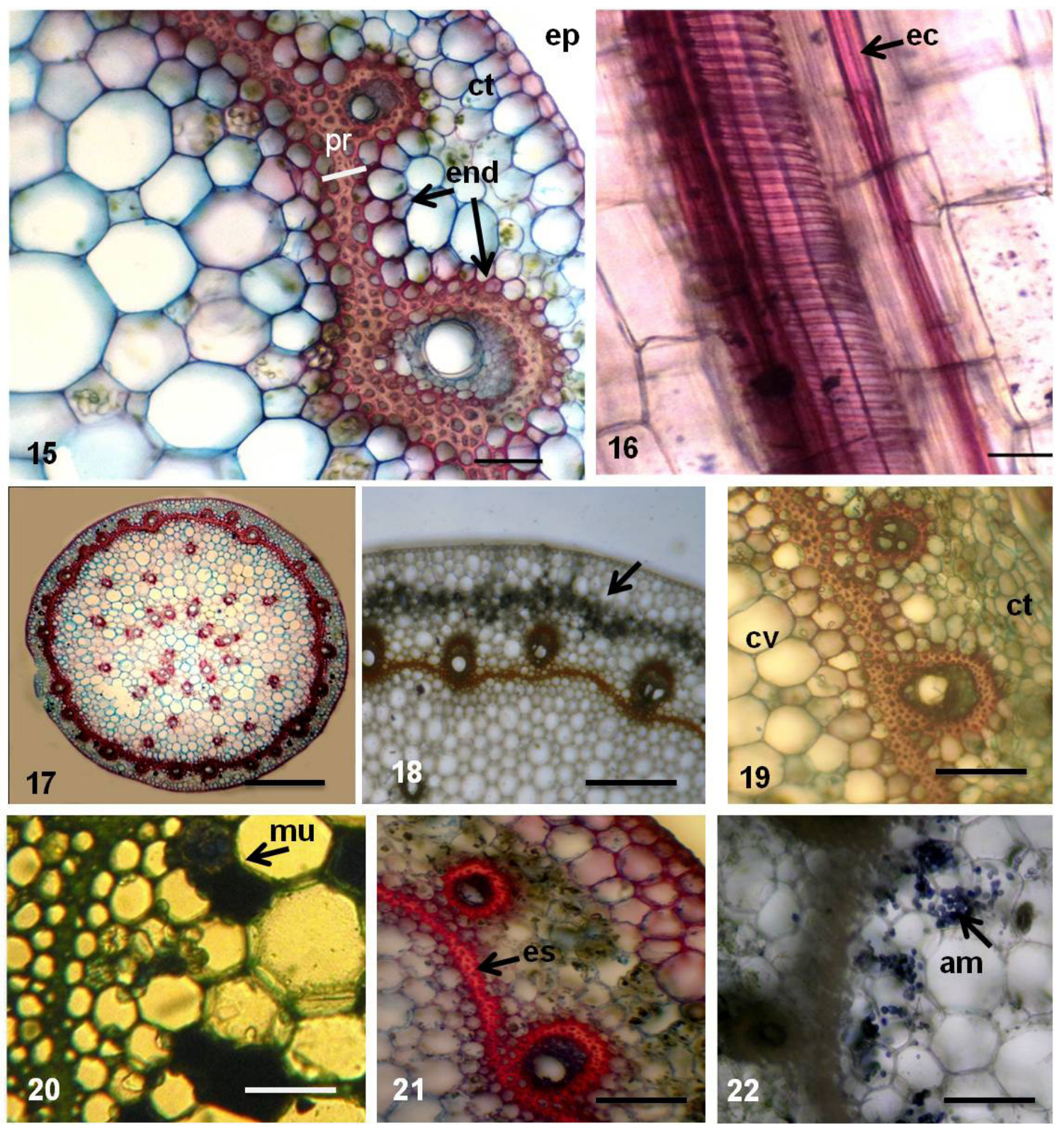

Figuras 15-22. Costus spicatus (Jacq.) Sw. 15. Secções transversais do caule: córtex (ct): epiderme (ep), endoderme (end), periciclo (pr). 16. Secção longitudinal do caule com estrias de Caspary (ec) na endoderme. 17-22. Secções transversais do caule: 17. Visão geral do caule 18. Compostos fenólicos em células da região cortical. 19. Células do córtex e cilindro vascular (cv) contendo alcaloides. 20. Células do cilindro vascular contendo mucilagem (mu). 21. Bainha pericíclica lignificada (bl). 22. Parênquima medular contendo amido corado com lugol (am). Barras $=5 \mu \mathrm{m}(17), 100 \mu \mathrm{m}(15,18,19,20,21,22), 200 \mu \mathrm{m}(18)$.

células com paredes espessadas e suberificadas constituindo o súber estratificado (Figura 27 e 28).

Na região cortical, há espaços intercelulares que variam na forma e tamanho (Figura 28). Segundo Oliveira et al. (1986) estes espaços constituem os meatos que resultam em grandes câmaras internas.

A endoderme é unisseriada com as estrias de Caspary evidentes, apresentando deposição de lignina num arranjo em formato de "U". O periciclo consiste em uma camada unisseriada de células com paredes delgadas de formato retangular, situado internamente à endoderme, responsáveis pela formação das raízes laterais (Figura 26 e 29).

O tecido vascular está organizado na forma de um arco com cerca de 10 polos de protoxilema classificada como poliarca. Os cordões de floema alternam-se com o xilema. A medula é formada por parênquima com células de paredes espessadas e lignificadas coradas de rosa com fluroglucinol (Figura 29).

As células parenquimáticas do córtex e da medula reagiram positivamente aos testes 


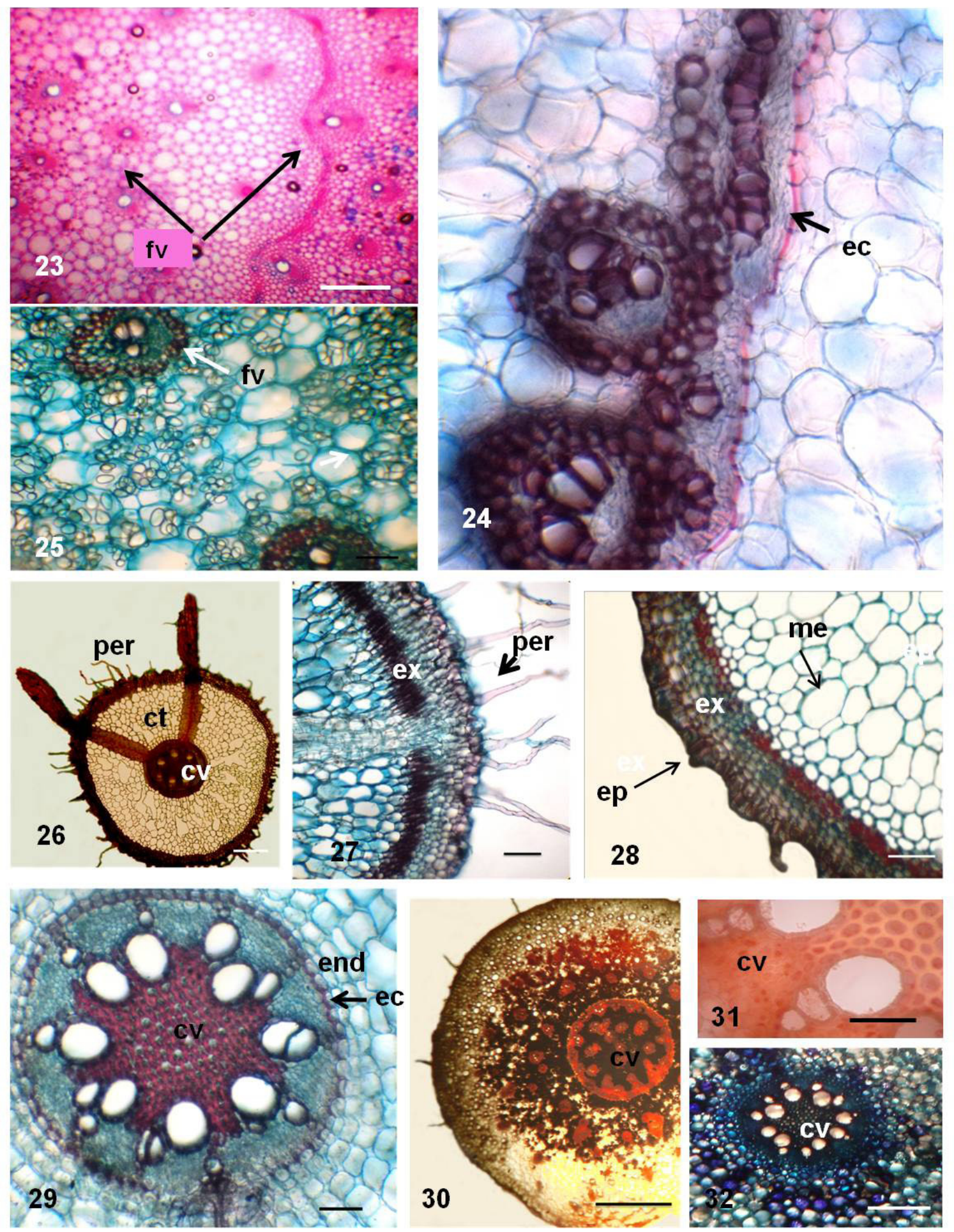

FIGURAS 23-32. Costus spicatus (Jacq.) Sw. 23-25. Secções transversais do rizoma. 23. Feixes vasculares (fv). 24. Endoderme e Estrias de Caspary (ec) 25. Feixes vasculares e células com grãos de amido. 26-32. Secções transversais da raiz. 26. Visão geral da raiz: pêlos radiculares (per), córtex (ct), cilindro vascular (cv). 27. Epiderme e pêlos radiculares. 28. Detalhe da exoderme (ex) e dos meatos (me). 29. Cilindro vascular (cv): endoderme (end), Estrias de Caspary (ec). 30. Distribuição de amido nas células cilindro vascular. 31. Proteínas estruturais no cilindro vascular. 32. Células do cilindro vascular e córtex contendo mucilagem. Barras $=100 \mu \mathrm{m}$ $(23,24,25,27,28,29) .200 \mu \mathrm{m}(31), 5 \mu \mathrm{m}(26,30,32)$. 
histoquímicos evidenciando a presença de amido (Figura 30), proteína estrutural (Figura 31) e mucilagem (Figura 32).

\section{Prospecção fitoquímica}

O extrato aquoso e etanólico dos órgãos vegetativos de $C$. spicatus indicam a presença de diferentes classes de substâncias tais como polifenóis ou compostos fenólicos, saponinas e heterosídeos cianogênicos em todos os órgãos vegetativos da espécie estudada neste trabalho (Tabela 2).

Para Bernards (2010) os compostos secundários das plantas são classificados de acordo com o tipo estrutural e pela origem biossintética e desempenham funções de compostos protetores ou de sinalização entre organismos. Segundo Kaufman et al. (1998), estas substâncias constituem um importante papel ecológico como estratégias reprodutivas e de defesa contra herbivoria.

Dentre as classes de substâncias evidenciadas pela prospecção química de $C$. spicatus os flavonoides, representados pela presença das leucoantocianidinas, e flavanonas, estão presentes em todas as partes vegetativas (raízes, rizoma, caule e folhas) analisadas. Os resultados descritos acima corroboram em parte com as observações realizadas por Willians \& Harborne (1977) os quais descrevem a presença dos flavonoides C-glicosideos (taxa de $86 \%$ ) isolados de folhas das Costoideae e por Pinna et al. (2008).

Os alcaloides foram detectados apenas nos extratos de caules, raízes e rizoma e estes resultados divergem quanto a localização encontrada por Pinna et al. (2008), o qual observou a presença desta classe no extratos foliares de $C$. spicatus.

A presença das saponinas é descrita por Martins et al. (2010) para folhas e rizomas de Hedychium coronarium da família Zingiberaceae. A presença de saponinas nas partes vegetativas de C. spicatus provavelmente é uma característica comum às Zingiberales e trata-se de um indicativo de diversas ações biológicas, tais como atividade antimicrobiana e inseticida, uma das propriedades relatadas para os terpenos (Viegas Junior, 2003).

Heterosídeos cianogênicos foram detectados no extrato aquoso de todas as partes vegetativas de $C$. spicatus. De acordo com Gleason (2011), a presença de tais substâncias é um indicativo que há liberação de ácido cianogênico, sendo produzidas por vários tecidos de plantas, porém mais frequentes em sementes. Para Kaufman et al. (1998) são compostos utilizados como defesa química.

Os resultados obtidos neste estudo possibilitam a compreensão dos arranjos celulares e das reservas de metabólitos secundários de C. spicatus. Tais informações fornecem um direcionamento para estudos químicos, agronômicos e fisiológicos, pois permitem a visualização das substâncias do metabolismo secundário nas partes vegetativas (raízes, rizomas, caules e folhas) ampliando informações de classes químicas que até o momento só haviam sido descritas apenas para as

TABELA 2. Metabólitos secundários encontrados no extrato etanólico e aquoso de raízes (raiz+rizoma), caule e folhas de C. spicatus (Jacq.) Sw

\begin{tabular}{|c|c|c|c|c|c|c|c|}
\hline \multirow[t]{2}{*}{ Classes de Substâncias } & \multirow[t]{2}{*}{ Indicadores } & \multicolumn{3}{|c|}{ EXTRATO AQUOSO } & \multicolumn{3}{|c|}{ EXTRATO HIDROALCOÓLICC } \\
\hline & & $\begin{array}{l}\text { Raiz e } \\
\text { rizoma }\end{array}$ & Caule & Folha & $\begin{array}{l}\text { Raiz e } \\
\text { rizoma }\end{array}$ & Caule & Folha \\
\hline Fenóis & $\mathrm{FeCl}_{3}$ & NR & - & NR & + & + & + \\
\hline Taninos & $\mathrm{FeCl}_{3}$ & - & + & + & - & - & + \\
\hline Antocianinas & Variação de cor/pH & - & - & - & - & - & - \\
\hline Chalconas /Auronas & Variação de cor/pH & NR & NR & NR & - & - & - \\
\hline Leucoantocianidinas & Variação de cor/pH & NR & NR & NR & + & + & - \\
\hline Catequinas & Variação de cor/pH & NR & NR & NR & - & - & + \\
\hline Flavononas & Variação de cor/pH & NR & NR & NR & + & + & + \\
\hline Flavonóis, Flavanonas Flavanóis & Variação de cor/pH & NR & NR & NR & - & - & - \\
\hline Xantonas & Variação de cor/pH & NR & NR & NR & - & - & - \\
\hline Saponinas & Teste de Espuma & + & + & + & + & + & + \\
\hline Alcaloides & Dragendorff, Hager e Mayer & NR & NR & NR & - & + & + \\
\hline Heterosideos Cianogênicos & Papel picro-sódico & + & + & + & NR & NR & NR \\
\hline Ácidos voláteis & Papel pH & + & + & + & NR & NR & NR \\
\hline
\end{tabular}

$(+)$ = presença de substância $(-)$ = ausência de substância. NR: não realizados. 
folhas (Silva et al. 2000; Willians \& Harborne, 1977; Pinna et al. 2008)

De uma forma geral os resultados anatômicos e de prospecção química consolidam informações referentes à família Costaceae dando subsídios a estudos taxonômicos e de natureza química.

\section{AGRADECIMENTOS}

Ao Instituto Federal do Amazonas (IFAM), ao Laboratório de Botânica Agroflorestal (LABAF/ UFAM); a Fundação de Amparo à Pesquisa (FAPEAM), ao Museu Paraense Emílio Goeldi e ao Programa de Pós-Graduação em Agronomia Tropical/UFAM.

\section{REFERÊNCIA}

ALBUQUERQUE, J.N. Plantas medicinais de uso popular. Brasília: ABEAS, 1989. 100p.

ALBUQUERQUE, L.S.B.; NEVES, L.J. Anatomia de Alpinia zerumbet (Pers.) Burtt Smith (Zingiberaceae). Acta Botanica Brasilica, v.18, n.1, p.109-121, 2004.

ANGIOSPERM PHYLOGENY GROUP - (APG III). An update of the angiosperm phylogeny group classification for the orders and families of flowering plants. Botanical Journal of the Linnean Society, v.161, p.105-121, 2009.

APPEZZATO-DA-GLÓRIA, B.; CARMELLO-GUERREIRO, S.M. Anatomia Vegetal. Viçosa: Editora UFV, 2006. 438p.

BERNARDS, M. A. Plant natural products: a primer. Canadian Journal of Zoology, v. 88, n. 7, p.601614, 2010.

BOORHEM, R.L. et al. Segredos e virtudes das plantas medicinais. Rio de Janeiro: Reader's Digest Brasil Ltda, 1999. 416p.

BORRÁS, M.R.L. Plantas da Amazônia: medicinais ou mágicas - Plantas comercializadas no mercado Adolpho Lisboa. Manaus: Valer, 2003. 322p.

COSTA, A. F. Farmacognosia. 2.ed. Lisboa: Fundação Calouste Gulbenkian, 1982. 1117p.

DAVID, R.; CARDE, J.P. Coloration différentielle des inclusions lipidiques et terpeniques des pseudophylles du Pin maritime au moyen du reactif Nadi. Comptes Rendus Hebdomadaires des Séances de l'Academie des Sciences Paris, vol.D, n.258, p. 1338-1340, 1964.

FRANCESCHI, V.R.; NAKATA, P.A. Calcium oxalate in plants: formation and function. Annual Review Plant Biology, v.56, p.41-71, 2005.

GASPARRI, S. Estudo da atividade antioxidante mutagênica/antimutagênica induzida pelo extrato vegetal da Costus. 2005. 78p. Dissertação (Mestrado - Área de concentração em Diagnóstico Genético e Molecular) - Universidade Luterana do Brasil, Canoas. GERLACH, D. Plant histochemistry and citochemistry. New York: Academic Press, 1984. 301p.

GLEASON, F.K. Plant Biochemisty. University of Minnesota. Jone \& Bartlet press, 2011. 248p.

HUSSIN, K.H. et al. Comparative leaf anatomy of Alpinia Roxb. species (Zingiberaceae) from China. Botanical
Journal of the Linnean Society, v.133, n.2, p.161180. 2000.

JENSEN, W.A. Botanical histochemistry. San Francisco: H.H. Freeman and Company, 1962. 480p.

JOHANSEN, D.A. Plant microtechnique. New York: McGraw-Hill Book Company Inc., 1940. 523p.

KAUFMAN P.B.; CSEKE, L.J.; DUKE, J.A. BRIELMANN, H.L. Natural products from plants. London New York: CRC Press.,1998. 632p.

KELLER, A.C. et al. Costus spicatus tea failed to improve diabetic progression in C57BLKS/J db/db mice, a model of type 2 diabetes mellitus. Journal of Ethnopharmacology, v.121, n.2, p.248-254, 2009.

KRAUS, J.E.; ARDUIN, M. Manual básico de métodos em morfologia vegetal. Seropédica: EDUR, 1997. 198p.

LORENZI, H.; MATOS, F.J.A. Plantas medicinais no Brasil: nativas e exóticas. 2.ed. Nova Odessa, SP: Instituto Plantarum, 2008. 544p.

MACE, M.E.; HOWELL, C.R. Histochemistry and identification of condensed tannin precursor in roots of cotton seedlings. Phytopathology, v.64, p.1297-1302, 1974.

MARTINS, M.B.G. et al. Caracterização anatômica e fitoquimica de folhas e rizomas de Hedychium coronarium J. Koining (Zingiberaceae) Revista Brasileira de Plantas Medicinais, v.12, n.2, p.179187, 2010.

MATOS, F.J.A. Introdução à fitoquímica experimental. Fortaleza: $2^{\circ}$ Edições UFC, 1997. 126p.

MENEZES, N.L. et al. Meristematic activity of the endodermis and the pericycle in the primary thickening in monocotyledons considerations on the "PTM". Anais da Academia Brasileira de Ciências, v.77, n.2, p.259274, 2005.

O'BRIEN, T.P. \& MCCULLY, M.E. The study of plant structure principles and selected methods. Melbourne: Termarcarphi Pty. Ltda,1981. 316p.

OLIVEIRA, F. et al. Caracterização morfológica de canado-brejo. Revista Brasileira de Farmacognosia, v.186, n.2, p.123-135, 1986

PETERSEN, O. G. Costus spicatus (Zingiberaceae). Flora Brasiliensis, v.3, n.3, p.52, 1990.

PINNA, F.L. et al. Prospecção fitoquímica e avaliação da atividade cicatrizante do spray a base de Costus spicatus Jacq. In: REUNIÃO ANUAL DA SOCIEDADE BRASILEIRA DE QUÍMICA, 31., 2008. São Paulo, Painéis. São Paulo: Adaltech, 2008.

SALATINO, A.; SILVA, J.B. Anatomia e óleos essenciais de folhas de Piper regnella (Miq) C. DC. var. regnella. Boletim de Botânica Universidade de São Paulo, v.3, n.1, p.95-106, 1975.

SILVA, B.P. et al. Flavonol glycosides from Costus spicatus. Phytochemistry, v.53, n.1, p.87-92, 2000.

SILVA, C.G. DA. O espessamento primário no sistema caulinar e a continuidade entre estes tecidos nos órgãos vegetativos de Zingiberaceae e Costaceae: enfoque nos tecidos da endoderme e periciclo. 2009. 212p. Dissertação (Mestrado - Área de concentração Anatomia de plantas vasculares) - Instituto de Biociências, Universidade de São Paulo, São Paulo.

SILVA, L.N. Aspectos anatômicos e etnofarmacológicos de Bonamia ferruginea (Choisy) Hallier (Convolvulaceae). 2004.100p. Dissertação (Mestrado -

Rev. Bras. PI. Med., Campinas, v.15, n.3, p.380-390, 2013. 
Área de concentração em Botânica) - Departamento de Botânica, Instituto Nacional de Pesquisa da Amazônia, Manaus.

SILVEIRA, G.O. et al. Lack of antidiabetic activity of the methanol extract of Costus spicatus in rats. Scientia Plena, v.6, n.12, p.1- 6, 2010.

SPECHT, C.D. et al. A molecular phylogeny of Costaceae (Zingiberales). Molecular Phylogenetics and Evolution, v. 21, n. 3, p.33-345, 2001.

SPECHT, C.D; STEVENSON, W. A new phylogeny-based generic classification of Costaceae (Zingiberales). Taxon, v.55, n.1, p.153-163, 2006.

THEOBALD, W.L.; KRAHULIK, J.L.; ROLLINS, R.C. Trichome description and classification. In: METCALFE,
C.R.; CHALK, L. Anatomy of the dicotyledons. v.1. Oxford: Claredon Press, 1979. p.40-53.

TOMLINSON, P.B. Phylogeny of the scitamineae morphological and anatomical consideration. Evolution, v.16, n.2, p.192-213, 1962.

TOMLINSON, P.B. Studies in the systematic anatomy of the Zingiberaceae. Journal of the Linnean Society, v.55, n.1, p.547-592, 1956.

VIEGAS JUNIOR, Cláudio. Terpenos com atividade inseticida: uma alternativa para o controle químico de insetos. Quím. Nova. v. 26, n.3, p. 390-400. 2003.

WILLIANS, C.A.; HARBORNE, J.B. The leaf flavonoids of the Zingiberales. Biochemical Systematics and Ecology, v.5, p.221-9, 1977. 